\title{
Associação entre otites bacterianas e infecção pelo circovírus suíno tipo 2 (PCV2) em suínos ${ }^{1}$
}

\author{
William Asanome ${ }^{2}$, Felipe L. Koller², Evandro Nottar², Fabiano B. Carregaro², \\ André Corrêa ${ }^{3}$, Priscila Zlotowski ${ }^{3}$, David Driemeier ${ }^{3}$ e David E.S.N. \\ de Barcellos ${ }^{*}$
}

\begin{abstract}
Asanome W., Koller F.L., Nottar E., Carregaro F.B., Corrêa A.M.R., Zlotowski P., Driemeier D. \& Barcellos D.E.S.N. 2008. [Association between bacterial otitis and porcine circovirus 2 (PCV2) infection in pigs.] Associação entre otites bacterianas e infecção pelo circovírus suíno tipo 2 (PCV2) em suínos. Pesquisa Veterinária Brasileira 28(10):471-476. Setor de Suínos, Faculdade de Veterinária, Universidade Federal do Rio Grande do Sul, Av. Bento Gonçalves 9090, Porto Alegre, RS 91540-000, Brazil. E-mail: davidbarcellos@terra.com.br

The occurrence and bacteriology of purulent otitis in groups of pigs affected by three different clinical conditions are described: postweaning multisystemic wasting syndrome (PMWS), depressed growth (attrition) and normal growth (control). A total of 385 animals, 60-130 days of age, were examined. Diagnosis of PMWS was confirmed by the presence of clinical signs and pathological findings compatible with the disease, and through detection of viral antigens in tissues by immunohistochemistry. From 242 pigs with PMWS, $57(23.5 \%)$ showed purulent lesions in the middle ear. Among 119 pigs with attrition, only $1(0.7 \%)$ presented the lesion. In 24 control pigs, middle ear lesions were not detected. The most frequently isolated agents from the lesions were Arcanobacterium pyogenes (43\%), á-hemolytic Streptococci (37.2\%) and Pasteurella multocida (27.9\%) out of 86 materials. The frequent occurrence of purulent lesions in the middle ear of PMWS affected pigs suggests that PCV2 infection may increase the susceptibility to bacterial otitis. The low occurrence of this disease in piglets with attrition suggests that otitis does not represent a significant cause for depressed growth in pigs from growing and finishing age. The isolation of $A$. pyogenes, á-hemolytic Streptococci and $P$. multocida from most of the lesions emphasizes the importance of these organisms as causal agents of otitis media in swine.
\end{abstract}

INDEX TERMS: Otitis media, PCV2, PMWS, PCVAD, growth depression, attrition, bacteriology, swine.

RESUMO.- Neste trabalho, foi estudada a ocorrência e a bacteriologia das otites purulentas em suínos apresentando três condições clínico-patológicas distintas: síndrome multissistêmica do definhamento dos suínos

\footnotetext{
${ }^{1}$ Recebido em 25 de março de 2008.

Aceito para publicação em 16 de maio de 2008.

2 Setor de Suínos, Faculdade de Veterinária, Universidade Federal do Rio Grande do Sul (UFRGS), Avenida Bento Gonçalves 9090, Porto Alegre, RS 91540-000, Brasil. Autor para correspondência: davidbarcellos@terra.com.br

${ }^{3}$ Setor de Patologia Veterinária (SPV), Faculdade de Veterinária, UFRGS, Porto Alegre, RS.
}

(SMDS), crescimento retardado (porém sem apresentação de sinais clínicos da SMDS) e crescimento normal. No total, foram examinados 385 animais com idade de 60-130 dias, sendo a confirmação do diagnóstico da SMDS obtida pelos sinais clínicos e achados patológicos e pela detecção de antígenos virais por imunoistoquímica. De 242 animais com a SMDS, 57 (23,5\%) apresentaram lesões purulentas no ouvido médio. Entre os 119 animais de baixo desenvolvimento, apenas $1(0,7 \%)$ apresentou a lesão. Não foram detectadas lesões macroscópicas no ouvido médio dos 24 animais com crescimento normal. Os agentes isolados com maior freqüência foram Arcanobacterium pyogenes (43\%), Streptococcus $\alpha$-hemolíti- 
$\cos (37,2 \%)$ e Pasteurella multocida $(27,9 \%)$ dos 86 ouvidos submetidos à bacteriologia. A alta ocorrência de lesões purulentas no ouvido médio de animais com a SMDS sugere que a infecção pelo PCV2 pode tornar o suíno mais suscetível às otites bacterianas. A ocorrência reduzida dessas lesões em suínos de baixo desenvolvimento, sem a manifestação clínica da SMDS, sugere que a otite média não representa uma causa importante de mau desempenho em leitões nas fases de crescimento e terminação. O envolvimento de $A$. pyogenes, Streptococcus $\alpha$-hemolíticos e $P$. multocida na maioria das lesões apontam a importância desses organismos como agentes causais de otite média em suínos.

TERMOS DE INDEXAÇÃO: Otite média, PCV2, PCVAD, SMDS, baixo desenvolvimento; bacteriologia, suínos.

\section{INTRODUÇÃO}

Atualmente a Síndrome Multissistêmica do Definhamento dos Suínos (SMDS) tem distribuição mundial e é considerada endêmica em muitos países produtores de suínos (Chae 2004), incluindo o Brasil, onde tem causado sérios prejuízos econômicos (Zanella \& Morés 2003). O agente etiológico da SMDS é o circovírus suíno tipo 2 (PCV2), que também tem sido associado a outras condições clínicas e patológicas, como a Síndrome da Dermatite e Nefropatia (PDNS), o Complexo de Doenças Respiratórias dos Suínos (PRDC), falhas reprodutivas, enterite granulomatosa e linfadenite necrosante (Chae 2005). A infecção se caracteriza por lesões nos tecidos linfóides, onde se observam graus variáveis de depleção linfocitária, perda da arquitetura folicular e infiltração multifocal ou difusa de histiócitos e/ou células gigantes multinucleadas (Segalés et al. 2004a). Infecções virais e bacterianas associadas ao PCV2 ocorrem com freqüência em rebanhos afetados pela SMDS (Segalés et al. 2005), predispostas por um estado de imunodepressão induzido pelo PCV2 (Segalés et al. 2004b).

As doenças do ouvido dos suínos têm recebido pouca atenção veterinária por envolverem órgãos de difícil acesso ao exame e por, aparentemente, não estarem associadas com perdas econômicas significativas. Achados patológicos e microbiológicos sugerem que a infecção do ouvido médio é resultado da ascensão de bactérias do trato respiratório superior através da tuba auditiva (Shimada et al. 1992). Os organismos que têm sido isolados dessas lesões incluem bactérias comumente encontradas na nasofaringe de animais saudáveis ou com doença respiratória, como Pasteurella (P.) multocida, Streptococcus spp., Staphylococcus spp., corineformes do grupo E, Fusobacterium (F.) necrophorum, Pseudomonas ( $P$.) aeruginosa, Actinobacillus ( $A$.) pleuropneumoniae, Arcanobacterium (A.) pyogenes e Mycoplasma (M.) hyorhinis (Hipólito et al. 1958, Olson 1981, Desrosiers 1985, Shimada et al. 1992, Morita et al. 1995, Duff et al. 1996, Harlizius et al. 1996). Por difusão a partir do ouvido médio, a infecção pode atingir estruturas do ouvido inter- no e do sistema nervoso, causando síndrome vestibular, que é caracterizada por inclinação da cabeça para o lado correspondente à lesão, andar em círculos, falta de equilíbrio, nistagmo e ptose palpebral e auricular (Hipólito et al. 1958, Olson 1981, Desrosiers 1985, Shimada et al. 1992, Duff et al. 1996, Harlizius et al. 1996).

Até o momento, não foi analisada a associação entre a otite média em suínos e a infecção com o PCV2. O objetivo do presente trabalho foi determinar a ocorrência e os agentes bacterianos envolvidos nas infecções purulentas do ouvido médio em três grupos distintos: suínos apresentando a SMDS; suínos de baixo desenvolvimento, porém sem sinais clínicos da SMDS; e suínos clinicamente sadios.

\section{MATERIAL E MÉTODOS}

Foram necropsiados 385 suínos, oriundos de 66 granjas localizadas no estado do Rio Grande do Sul, Brasil. Duzentos e quarenta e dois animais, com idades variando entre 60 e 100 dias, apresentavam sinais clínicos da SMDS, que incluíam má condição corporal, atraso no crescimento, linfonodos inguinais aumentados, dispnéia, diarréia e palidez cutânea. Dentre estes, três demonstravam sinais de síndrome vestibular, com torção de cabeça, ptose palpebral, andar em círculos, desequilíbrio e queda freqüente (Fig.1). Foram investigados outros dois grupos, compostos respectivamente, por 119 animais apresentando baixo desenvolvimento (pelo menos $20 \%$ de peso a menos do que a média do lote), porém sem definhamento característico da SMDS e 24 com crescimento normal (controles). Nestes dois últimos grupos, as idades variavam entre 85 e 130 dias e não foram notados sinais clínicos evidentes da SMDS ou de síndrome vestibular.

O exame macroscópico dos animais foi realizado após eutanásia com choque elétrico e sangria. Fragmentos de pele, tonsilas, linfonodos mesentéricos, baço, intestinos, fígado, estômago, rins, pulmão, coração e sistema nervoso central foram coletados, fixados em formalina tamponada a $10 \%$ e processados por métodos convencionais para histologia, utilizando as colorações de hematoxilina-eosina (HE) e ácido periódico de

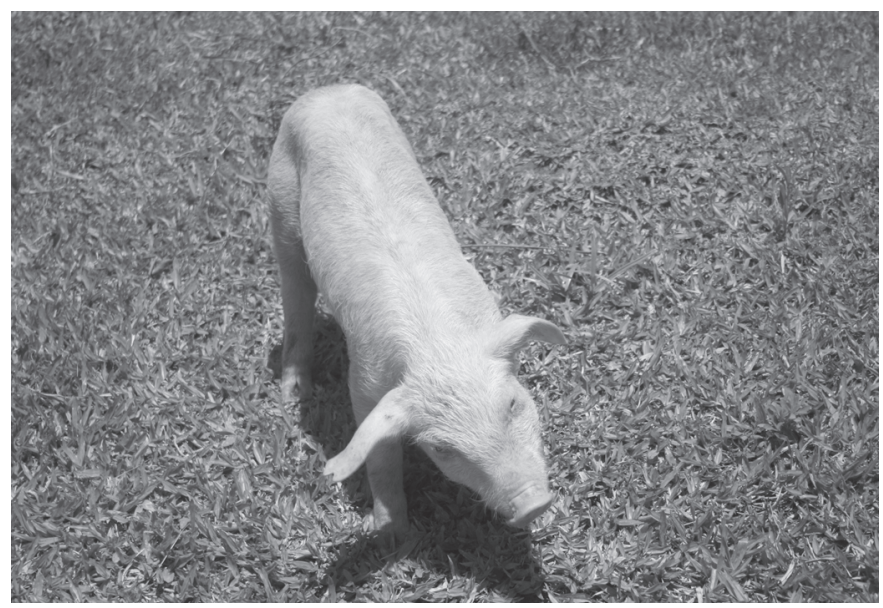

Fig.1. Leitão apresentando síndrome vestibular. Inclinação da cabeça e queda da orelha para o lado afetado (ptose auricular). 
Schiff (PAS) (Prophet et al. 1992). A imunoistoquímica para PCV2 foi realizada com anticorpo policlonal anti-PCV2 (Sorden et al. 1999) com uma diluição de 1:1000 utilizando Protease XIV (Sigma) como recuperador antigênico e DAB (tetrahidrocloreto de 3,5-diamino-benzidina) (DAKO) como cromógeno. Foram considerados positivos para a SMDS os animais que apresentaram sinais clínicos e achados patológicos compatíveis com a doença e antígeno viral nas respectivas lesões (Chae 2005).

O exame do ouvido médio foi realizado através de dois cortes no crânio com serra manual: o primeiro, no plano horizontal, na porção ventral das bulas timpânicas; o segundo, transversal do crânio, alguns milímetros à frente da abertura dos condutos auditivos externos. Com esses acessos, buscou-se verificar a existência de exsudato purulento no interior da cavidade e/ou bula timpânica, que quando presente foi coletado assepticamente e cultivado em ágar-sangue de carneiro $5 \%$ e em ágar MacConkey, a $37^{\circ} \mathrm{C}$, em atmosfera aeróbica. $\mathrm{O}$ crescimento foi avaliado até 96 horas e a identificação dos organismos isolados foi realizada segundo métodos padrões (Barrow \& Feltham 1999). A relação entre a presença de otites purulentas e a SMDS foi analisada pelo teste de Fisher, sendo considerada diferença significativa para um valor de $\mathrm{P}<0,05$.

\section{RESULTADOS}

\section{Achados macroscópicos e microscópicos}

A ocorrência das lesões nos três grupos analisados e os resultados gerais da bacteriologia está apresentada nos Quadros 1 e 2, respectivamente.

Entre os 242 animais com sinais clínicos de SMDS, $189(78 \%)$ apresentavam lesões macro e microscópicas compatíveis com as da infecção pelo PCV2, predominando as alterações nos órgãos linfóides, pulmão, rins e fígado. Na análise macroscópica, os linfonodos apresentaram-se aumentados de tamanho e, em alguns casos, congestos ou hemorrágicos. Microscopicamente, as lesões nesses órgãos e em outros tecidos linfóides caracterizaram-se por depleção linfocitária e infiltrado linfo-histiocitário ou granulomatoso de graus variáveis, com presença freqüente de inclusões basofílicas de tamanhos variados e células gigantes multinucleadas. Nos casos de conges-

Quadro 1. Ocorrência e apresentação clínica da otite média purulenta em suínos com idades entre 60-130 dias, provenientes de 66 granjas do estado do Rio Grande do Sul, Brasil

\begin{tabular}{ccc}
\hline Grupo & $\begin{array}{c}\text { Ocorrência da } \\
\text { otite média } \\
\text { purulenta/grupo }\end{array}$ & $\begin{array}{c}\text { Apresentação } \\
\text { da síndrome } \\
\text { vestibular }\end{array}$ \\
\hline $\begin{array}{c}\text { Suínos com sinais clínicos e lesões ca- } \\
\text { racterísticos da SMDS }\end{array}$ & $57(23,5 \%)^{\mathrm{a}}$ & $3 / 57(5,3 \%)$ \\
$\begin{array}{c}\text { Suínos de baixo desenvolvimento, mas } \\
\text { sem manifestação clínica da SMDS } \\
(n=119)\end{array}$ & $1(0,84 \%)^{\mathrm{b}}$ & 0 \\
$\begin{array}{l}\text { Suínos com crescimento normal }(\mathrm{n}=24) \\
\text { Total }\end{array}$ & $\begin{array}{c}0(0 \%)^{\mathrm{b}} \\
68(15,1 \%)\end{array}$ & 0 \\
\hline
\end{tabular}

* SMDS = Síndrome do Definhamento Multissistêmico dos Suínos.

$a, b$ Letras diferentes indicam diferença significativa $(p<0,05)$ pelo teste de Fisher.
Quadro 2. Agentes bacterianos isolados da cavidade/bula timpânica $(n=86)$ de suínos com otite média purulenta

\begin{tabular}{lcc}
\hline \multicolumn{1}{c}{ Agente } & Ouvidos afetados & $\%$ \\
\hline Arcanobacterium pyogenes & 37 & $43,0 \%$ \\
Streptococcus á hemoliticos & 32 & $37,2 \%$ \\
Pasteurella multocida & 24 & $27,9 \%$ \\
Escherichia coli & 4 & $4,6 \%$ \\
Corynebacterium sp. & 1 & $1,2 \%$ \\
Crescimento negativo & 9 & $10,5 \%$ \\
Inconclusivo & 8 & $9,3 \%$
\end{tabular}

tão e hemorragia de linfonodos, observou-se necrose de coagulação, que também foi notada no baço, quando este se apresentava aumentado e com áreas de infarto no exame macroscópico. No tórax, na grande maioria dos casos, os pulmões se mostraram não colapsados e com edema interlobular, bem como, com áreas de consolidação crânio-ventrais, lesões que coincidiram histologicamente com pneumonia intersticial e broncopneumonia purulenta, respectivamente. Nos rins, as lesões mais evidentes foram o aumento de tamanho e superfície capsular com pontos brancos, achados que corresponderam, na histologia, à nefrite tubulointersticial mononuclear. As alterações no fígado incluíram redução de tamanho, presença de manchas vermelho-escuras no parênquima e, eventualmente, icterícia. As lesões microscópicas encontradas no órgão foram hepatite periportal e necrose individual de hepatócitos. O exame imuno-histoquímico mostrou a presença do antígeno do PCV2 na maioria das lesões histológicas características encontradas nos órgãos linfóides (tonsila, baço, e linfonodo mesentérico), pulmão, rins, fígado e intestino.

Em 87 (73\%) suínos com baixo desenvolvimento e em $5(20,8 \%)$ suínos com crescimento normal (grupo controle) foram observadas lesões macro e microscópicas compatíveis com a infecção pelo PCV2. Em ambos os grupos, predominaram as alterações de grau leve. Os demais animais do grupo controle não apresentaram lesões patológicas significativas.

\section{Lesões macroscópicas no ouvido médio}

Dos 242 animais apresentando sinais clínicos e lesões características da SMDS, $57(23,5 \%)$ tinham otite média purulenta (Fig.2), dentre esses $30(52,6 \%)$ apresentavam lesão bilateral, resultando num total de 87 ouvidos afetados. Em 6 ouvidos, observou-se lise da parede ventral da bula timpânica, evidenciada pela formação de abscesso no tecido subjacente ou pela fragilidade e/ou deformidade na superfície externa dessa estrutura e nos demais (81) se notou apenas a presença de exsudato purulento na bula ou na cavidade timpânica, sem lesões aparentes das estruturas internas do ouvido. Nos exames bacteriológicos, foram obtidas culturas puras ou mistas com até duas bactérias diferentes. Os agentes isolados com maior freqüência foram A. pyogenes, Streptococcus $\alpha$-hemolíticos e $P$. multocida, encontrados em, respectivamente, $36(42,3 \%), 32(37,6 \%)$ e $24(28,2 \%)$ dos 85 ouvidos submetidos à bacteriologia (Quadro 2). 


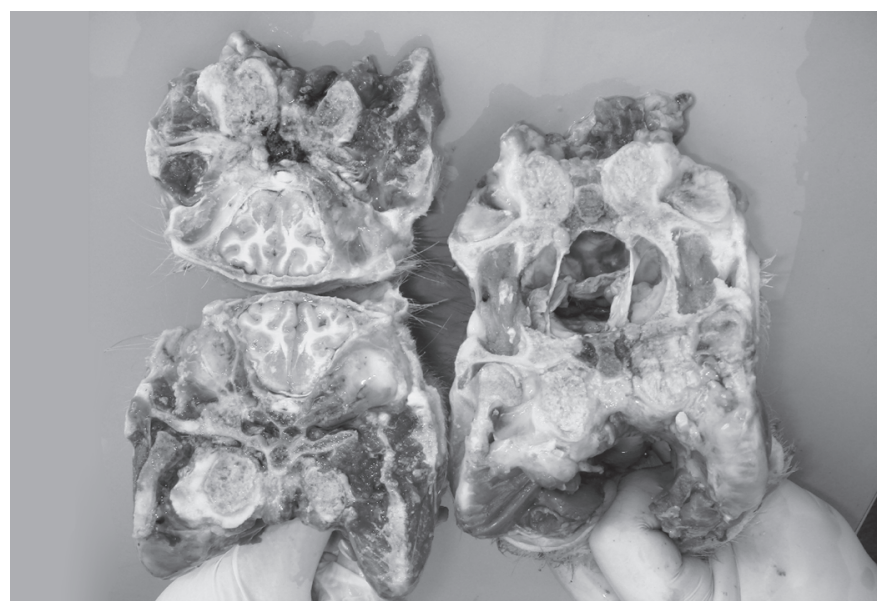

Fig.2. Conteúdo purulento na bula timpânica de dois suínos apresentando infecção do ouvido médio. Peça da esquerda: Otite média purulenta unilateral com formação de abscesso. Peça da direita: Otite média purulenta bilateral.

No grupo composto por 119 animais de baixo desenvolvimento, sem sinais clínicos da SMDS, apenas 1 apresentou otite média purulenta. Nesse único caso, a lesão foi unilateral, caracterizada pela presença de exsudato purulento na cavidade timpânica e houve isolamento de $A$. pyogenes em cultura pura. Os animais com crescimento normal não apresentaram lesões macroscópicas no ouvido médio.

\section{DISCUSSÃO}

A presença de sinais clínicos e lesões patológicas características, associadas à detecção do antígeno do PCV2 em $78 \%$ dos animais, confirmaram o diagnóstico da SMDS. Embora tenham sido observadas lesões histológicas discretas e presença do antígeno viral em alguns suínos dos outros dois grupos estudados (baixo desenvolvimento e de crescimento normal), não foram notados definhamento, refugagem e dispnéia nos mesmos, o que sugere a apresentação da doença na sua forma subclínica, em estágio inicial de evolução ou em remissão. Segundo Nottar (2007), a infecção pelo PCV2, mesmo quando não associada às manifestações clínicas da SMDS, pode ser uma causa de baixo desempenho em suínos nas fases de recria e terminação. A razão pela qual apenas alguns entre os animais infectados pelo PCV2 desenvolvem a doença na sua forma aparente ainda não está clara. Há indícios de que um perfil alterado de citocinas nos tecidos linfóides de determinados indivíduos - incluindo um aumento de interleucina 10 e a incapacidade de produzir interferon logo no início do processo infeccioso - esteja relacionado à expressão completa da SMDS (Segalés et al. 2005).

Infecções bacterianas concomitantes têm sido observadas com freqüência em rebanhos apresentando a SMDS, nos quais é comum a presença de doença de Glässer, salmonelose, meningite estreptocócica, colibacilose e pneumonia por M. hyopneumoniae, P. multocida,
Bordetella (B.) bronchiseptica e A. pleuropneumoniae (Madec et al. 2000, Kim et al. 2002, Pallarés et al. 2002, Segalés et al. 2005). No presente estudo, uma alta percentagem $(23,5 \%)$ de animais com a SMDS apresentou lesões purulentas no ouvido médio. Em contrapartida, a infecção foi observada em apenas um suíno $(0,84 \%)$ no grupo de baixo desenvolvimento e, no grupo controle, nenhum animal apresentou a lesão. A diferença estatisticamente significativa $(P<0,05)$ indica que os animais com a SMDS são mais suscetíveis às infecções do ouvido médio. Há vários aspectos clínicos, patológicos e imunológicos que apontam o PVC2 como responsável por um estado de imunodepressão do hospedeiro, ainda que não se conheçam perfeitamente os mecanismos pelos quais ele ocorre (Segalés et al. 2004b). Nos surtos de SMDS, é comum a presença de infecções bacterianas concorrentes, que não respondem ao tratamento com antimicrobianos (Segalés et al. 1997, Madec et al. 2000); ocorrência de infecções por agentes oportunistas como Pneumocystis carinii (Sanches 2007), Chlamydia spp. (Carrasco et al. 2000), Aspergillus spp. (Segalés et al. 2003), Cryptosporidium parvum (Núñes et al. 2003) e Candida albicans (Zlotowski et al. 2006); lesões severas nos tecidos linfóides causadas pelo PCV2, resultando em depleção linfocitária e alteração das populações de células circulantes do sistema imune (Segalés \& Clark 2002, McCullough et al. 2003); perfis alterados de expressão de citocinas em tecidos linfóides (Segalés \& Mateu 2006); e a observação de um efeito imunomodulatório do PCV2 sobre células especializadas em produção de interferon (NIPC, Natural Interferon Producing Cells) (Vincent et al. 2005).

Os resultados obtidos no presente trabalho constituem mais uma evidência do caráter imunodepressor que tem sido proposto para o PCV2. Os mecanismos de imunidade do ouvido médio são similares aos encontrados no aparelho respiratório e a mucosa da tuba auditiva é revestida por epitélio prismático ciliado e a submucosa possui células produtoras de muco e quantidades variáveis de folículos linfóides, concentrados na região da abertura nasofaringeal (Pracy et al. 1998). Achados patológicos e microbiológicos indicam que a otite média em suínos resulta da ascensão e estabelecimento de organismos da nasofaringe na tuba auditiva (Shimada et al. 1992). Animais com a SMDS provavelmente respondam de forma ineficiente frente aos estímulos antigênicos presentes na mucosa do ouvido médio, o que os tornaria mais predispostos à infecção.

Considerando-se a existência de uma estreita relação da otite média com pneumonias bacterianas e rinite atrófica (Olson 1981, Shimada et al. 1992, Duff et al. 1996), supõe-se que o PCV2 possa ter atuado aumentando a suscetibilidade a essas infecções respiratórias e, indiretamente, às infecções do ouvido médio.

Em humanos, a patogenia da otite média tem sido estudada extensamente. Acredita-se que infecções respiratórias virais tenham um papel fundamental para o desenvolvimento da doença, causando disfunções da tuba au- 
ditiva e permitindo o estabelecimento de infecções bacterianas secundárias (West 2002). Os mecanismos exatos pelos quais as infecções virais facilitam o estabelecimento da otite média não são conhecidos, mas sugere-se que a inflamação da mucosa respiratória resulte em obstrução da tuba auditiva e em formação de pressão negativa no ouvido médio, que passa a aspirar conteúdo da nasofaringe (Winther et al. 2002). O vírus sincicial respiratório (RSV) tem sido o mais freqüentemente associado com infecções do ouvido médio humano (NoksoKoivisto et al. 2006). Em contrapartida, não há dados na literatura que relacionem infecções respiratórias virais à ocorrência de otite média no suíno. Porém, um mecanismo semelhante de patogenia pode ser proposto para as otites observadas neste estudo. É possível que a hiperplasia do tecido linfóide da tuba auditiva, provocada pelo PCV2, tenha contribuído para a obstrução deste órgão, desencadeando a mesma seqüência de eventos que é observada durante a infecção do ouvido humano. A interação entre todos os fatores acima mencionados, que são direta ou indiretamente relacionados à infecção pelo PCV2, pode ter resultado numa maior predisposição dos animais com a SMDS à otite média. Ainda, cabe ressaltar que não se descarta a possibilidade do envolvimento de outros vírus associados a doenças respiratórias do suíno - tais como adenovírus, citomegalovírus ou vírus da influenza - na patogenia dos casos estudados no presente trabalho, já que não foram incluídas análises específicas para a detecção desses agentes.

A variedade de bactérias isoladas no presente estudo é a mesma obtida por outros autores que investigaram as lesões purulentas do ouvido médio do suíno (Hipólito et al. 1958, Olson 1981, Desrosiers 1985, Shimada et al. 1992, Harlizius et al. 1996). A ausência de crescimento em $10,6 \%$ das amostras pode estar relacionada com tratamento recente com antimicrobianos ou evidenciar a presença de organismos anaeróbicos ou fastidiosos, já que não foram utilizados processamentos laboratoriais que contemplassem essas exigências diferenciadas de crescimento.

Os cortes adotados para acesso ao ouvido médio não possibilitaram uma avaliação precisa da integridade de todas as suas estruturas. Entretanto, a existência de exsudato purulento na bula ou na cavidade timpânica é um indicativo de uma lesão de grau e extensão acentuada. Olson et al. (1981) e Shimada et al. (1992) relataram que a presença de inflamação supurativa do ouvido médio esteve freqüentemente associada à lise das estruturas ósseas que o compõe (ossículos, septos da bula e paredes da cavidade) e da membrana timpânica. Em seis dos animais examinados neste estudo, foi possível observar macroscopicamente a lise dos septos e da parede da bula timpânica. Apesar da gravidade das lesões, a observação de apenas três animais com sinais de síndrome vestibular indica que, na maioria dos casos, a infecção não se estendeu para o ouvido interno e para o sistema nervoso, ou que, pelo menos, não danificou as estruturas responsáveis pela manutenção do equilíbrio corporal.

Os resultados sugerem que animais com a SMDS podem ser mais suscetíveis às otites bacterianas. $O$ envolvimento de $A$. pyogenes, Streptococcus $\alpha$-hemolíticos e $P$. multocida na maioria das lesões apontam a importância desses organismos como agentes causais da otite média em suínos.

Agradecimentos.- Aos estagiários e funcionários dos setores de Suínos e de Patologia da Faculdade de Veterinária, UFRGS, pelo auxílio nas necropsias e pelas preparações histológicas. Às agroindústrias que disponibilizaram os animais para o estudo. À Coordenação de Aperfeiçoamento de Pessoal de Nível Superior (CAPES) pelo apoio financeiro.

\section{REFERÊNCIAS}

Barrow G.I. \& Feltham R.K.A. 1999. Cowan and Steel's Manual for the Identification of Medical Bacteria. $2^{\text {nd }}$ ed. Cambridge University Press, Cambridge. 331p.

Carrasco L., Segalés J., Bautista M. J., Gomez-Villamandos J. C., Rosell C., Ruiz-Villamor E. \& Sierra M.A. 2000. Intestinal chlamydial infection concurrent with postweaning multisystemic wasting syndrome in pigs. Vet. Rec. 146:21-23.

Chae C. 2004. Postweaning multisystemic wasting syndrome: A review of aetiology, diagnosis and pathology. Vet. J. 168:41-49.

Chae C. 2005. A review of porcine circovirus 2-associated syndromes and diseases. Vet. J. 169:326-336.

Desrosiers R. 1985. Les otites. Médicine Véterinaire, Québec, 15:201202.

Duff J.P., Scott W.A., Wilkes M.K. \& Hunt B. 1996. Otitis in weaned pig: A new pathological role for Actinobacillus (Haemophilus) pleuropneumoniae. Vet. Rec. 139:561-563.

Harlizius J., Kluczniok C. \& Bollwahn W. 1996. Clinical and Radiological Findings in Middle and Inner Ear Infections. Proc. $14^{\text {th }}$ IPVS Congress, Bologna, p.705.

Hipolito O., Lamas J.M. \& Godoy A.M. 1958. Otite média dos suínos. Arqs Esc. Superior Vet. Minas Gerais 11:351-356.

Kim J., Chung H., Jung T., Cho W., Choi C. \& Chae C. 2002. Postweaning multisystemic wasting syndrome of pigs in Korea: prevalence, microscopic lesions and coexisting microorganisms. J. Vet. Med. Sci. 64:57-62.

Madec F., Eveno E., Morvan P., Hamon L., Blanchard P., Cariolet R., Amenna N., Morvan H., Truong C., Mahé D., Albina E. \& Jestin A. 2000. Post-weaning multisystemic wasting syndrome (SMDS) in pigs in France: clinical observations from follow-up studies on affected farms. Livestock Production Science 63:223-233.

McCullough K.C., Vincent I.E., Summerfield A., Nielsen J., Krakowa S., Ellis J.A., Nauwynck H.J., Cherreyre C., McNelly F. \& Allan G.M. 2003. The immunology of PCV2 infections and SMDS, p.25-34. In: Merial (Ed.), PCV2 Diseases: Intimate relationships between host and pathogen and a close up on Asia. 4th Merial Symposium on SMDS, Seoul.

Morita T., Fukuda H., Awakura T., Shimada A., Umemura T., Kazama S. \& Yagihashi T. 1995. Demonstration of Mycoplasma hyorhinis as a possible primary pathogen for porcine otitis media. Vet. Pathol. 32:107-111.

Nokso-Koivisto J., Hovi T. \& Pitkäranta A. 2006. Viral upper respiratory tract infections in young children with emphasis on acute otitis media. Int. J. Pediatric Otorhinolaryngol. 70(8):1333-1342.

Nottar E. 2007. Avaliação de causas infecciosas de baixo desenvolvimento em suínos nas fases de recria e terminação. Dissertação de Mestrado, Programa de Pós-Graduação em Ciências Veterinárias, Universidade Federal do Rio Grande do Sul, Porto Alegre. 46p. 
Núñes A., Mcneilly F., Perea A., Sánchez-Cordón P.J., Huerta B., Allan G. \& Carrasco L. 2003. Coinfection by Cryptosporidium parvum and Porcine Circovirus Type 2 in Weaned Pigs. J. Vet. Med. B 50:255258.

Olson L.D. 1981. Gross and microscopic lesions of middle and inner ear infections in swine. Am. J. Vet. Res. 42:1433-1440.

Pallarés F.J., Halbur P.G., Opriessnig T., Sorden S.D., Villar D., Janke B.H., Yaeger M.J., Larson D.J., Schwartz K.J., Yoon K.J. \& Hoffman L.J. 2002. Porcine circovirus type 2 (PCV2) coinfections in US field cases of postweaning multisystemic wasting syndrome (SMDS). J. Vet. Diagn. Invest. 14:515-519.

Pracy J.P., White A., Mustafa Y., Smith D. \& Perry M.E. 1998. The comparative anatomy of the pig middle ear cavity: a model for middle ear inflammation in the human? J. Anat. 192:359-368.

Prophet E.B., Mills B., Arrington J.B. \& Sobin L.H. 1992. Laboratory Methods in Histotechnology. Armed Forces Institute of Pathology, American Registry of Pathology, Washington, DC. 279p.

Sanches E.M.C. 2007. Pneumocystis sp. e Circovírus (PCV2) em pulmões de suínos de abate, procedentes dos estados do Rio Grande do Sul e Mato Grosso e estudo das relações filogenéticas das amostras de Pneumocystis sp. Tese de Doutorado, Programa de Pós-Graduação em Ciências Veterinárias, Universidade Federal do Rio Grande do Sul, Porto Alegre.

Segalés J., Sitjar M., Domingo M., Dee S., Del Pozo M., Noval R., Sacristan C., De Las Heras A., Ferro A. \& Latimer K.S. 1997. First report of postweaning multisystemic wasting syndrome in pigs in Spain. Vet. Rec. 141:600-601.

Segalés J. \& Clark E.G. 2002. Immunostimulation and immunosuppression: two faces of the same coin, p.33-43. In: Merial (Ed.), SMDS and PCV2 Diseases: Beyond the debate. $3^{\text {rd }}$ Merial Symposium on SMDS, Ames.

Segalés J., Domingo M., Collell M., Jensen H.E. \& Blanco, J.L. 2003. Pulmonary aspergillosis in a postweaning multisystemic wasting syndrome (PMWS) affected pig. The Pig Journal 52:41-47.
Segalés J., Rosell C. \& Domingo M. 2004a. Pathological findings associated with naturally acquired porcine circovirus type 2 associated disease. Vet. Microbiol. 98:137-149.

Segalés J., Domingo M., Chianini F., Majó N., Domínguez J., Darwich L. \& Mateu E. 2004b. Immunosuppression in postweaning multisystemic wasting syndrome affected pigs. Vet. Microbiol. 98:151-158.

Segalés J., Allan G.M. \& Domingo M. 2005. Porcine circovirus diseases. Anim. Health Res. Rev. 6:119-142.

Segalés J. \& Mateu E. 2006. Immunosuppression as a feature of postweaning multisystemic wasting syndrome. Vet. J. 171:396-397.

Shimada A., Adachi T., Umemura T., Kohno K., Sakaguchi Y. \& Itakura Y. 1992. A pathologic and bacteriologic study on otitis media in swine. Vet. Pathol. 29:337-342.

Sorden S.D. 2000. Update on porcine circovirus and postweaning multisystemic wasting syndrome (SMDS). Swine Health and Production 8(3):136.

Vincent I.E., Carrasco C.P., Guzylack-Piriou L., Herrmann B., Mcneilly F., Allan G.M., Summerfield A. \& Mccullough K.C. 2005. Subsetdependent modulation of dendritic cell activity by PCV2. Immunology 115:388-398.

West J.V. 2002. Acute upper airway infections. Brit. Med. Bull. 61:215230.

Winther B., Hayden F., Arruda E., Dutkowski R., Ward P. \& Hendley O. 2002. Viral respiratory infection in schoolchildren: effects on middle ear pressure. Pediatrics 109:826-832.

Zanella J.RC. \& Morés N. 2003. Circovirose suína. Circular Técnica, Embrapa Suínos e Aves, Concórdia, SC. Disponível em <http:// www.cnpsa.embrapa.br/sgc/sgc_publicacoes/cit37.pdf> Acesso em 29 dez. 2006.

Zlotowski P., Rozza D.B., Pescador C.A., Barcellos D.E., Ferreiro L., Sanches E.M.C. \& Driemeier D. 2006. Muco-cutaneous candidiasis in two pigs with postweaning multisystemic wasting syndrome. Vet. J. 171:566-569. 